perspective and why the current NHS contract makes it difficult to employ substitutive approaches, in contrast to supplemental ones. ${ }^{1,2}$ The innovative use of skill mix has the potential to increase technical efficiency, lower costs and reduce inequalities in service delivery, but is underutilised in dentistry. ${ }^{3,4}$ Academic research into technical efficiency is becoming increasingly utilised in healthcare, ${ }^{5}$ yet given that GDPs operate as small discrete enterprises, they are also acutely sensitive to incentives within the NHS dental contract. ${ }^{6}$ This paper provided a very brief and basic introduction into the economics of skillmix. We intend to follow up this work with a Cochrane Effective Practice and Organisation of Care (EPOC) formal review entitled The impact of different methods of remuneration on the behaviour of general dental practitioners in primary dental care. This will provide an overview of the current evidence base for financial incentives on practitioners' behaviour and identify any gaps in our knowledge which need to be filled by future research.

1. Csikar JI, BradleyS, Williams SA, Godson JH, Rowbotham J S. Dental therapy in the United Kingdom: part 4. Teamwork - is it working for dental therapists? Br Dent J 2009: 207: 529-536.

2. Williams SA, Bradley S, Godson J H, Csikar JI, Rowbotham J S. Dental therapy in the United Kingdom: part 3. Financial aspects of current working practices. Br Dent J 2009: 207: 477-483.

3. Gallagher JE, Wilson N H. The future dental workforce? Br Dent J 2009;206: 195-200.

4. Farrell MJ. The measurement of productive efficiency. J Royal Statistical Society 1957; 120: 253-281.

5. Hollingsworth $B$, Street $A$. The market for efficiency analysis of health care organisations. Health Econ 2006:15: 1055-1059

6. Service Delivery and Organisation programme. The impact of incentives on the behaviour and performance of primary care professionals. Available at: http://www.sdo.nihr.ac.uk/files/project/SDO_FR_081618-158_V06.pdf. Accessed 7 March 2011.

DOI: 10.1038/sj.bdj.2011.527

\section{BUS DRIVER THREAT}

Sir, I was interested to read the opinion piece (Improving oral health among schoolchildren - which approach is best? BDJ 2011; 210: 59-61) referring to oral health improvement teams using modern inventions to suit the needs of the local population, using a multilevel approach and not using outdated methods.

I recall, as a community dentist in the 1980s, using a multilevel approach to try to improve the oral health of a group of adults in NE Hampshire who had moder- ate to severe learning disabilities. There were about 50 people in the group daily attending a new Centre where the person in charge and the staff were enthusiastic and caring. The majority of the people attending the Centre had poor/bad oral health and most had not accepted an offer of dental care provision.

It was felt that oral health promotion to parents, carers and all staff would produce an improvement in oral health of the group. Sessions to talk about how to improve oral health were set up with staff, parents and carers all invited (including catering staff, cleaner and groundsman at the Centre) and substantial numbers attended these discussions and appeared keen to act. Over the following six months an increasing number of those with learning disabilities accepted dental care and it was obvious that the general attitude of those at the Centre to oral health and treatment had undergone a significant transformation.

When returning the following year to encourage the few remaining people attending the Centre who had not had any dental care to do so, it was disappointing to find several were still not willing to accept dental care. I suspected that maybe some parents, or staff had not maintained their apparent enthusiasm for good oral health from the previous year, but further investigation failed to locate any lessening of the previous cooperation.

But, a little later, I did find the person who was giving a negative message, which had resulted in people not obtaining dental care. He was telling them that in his experience going to a dentist was to be avoided. He was the bus driver driving people to and from the Centre every day who had not been invited to the oral health discussions the previous year and had not been thought of as a member of this relatively closed group of people at the Centre.

R. Rippon, Malaga

DOI: 10.1038/sj.bdj.2011.528

\section{ANTIBACTERIAL TWIG}

Sir, in response to the request from $\mathrm{R}$. Carr (BDJ 2011; 210: 149) about a brown fibrous herb used by the Somali people to clean their teeth, I may be able to help. I have just returned from Lewa
Downs in Northern Kenya (only 200 miles from Somalia) where I ran a basic extraction clinic (with an Aid Kit from Dentaid and sponsorship from Dental Directory) and where the local Maasai and Samburu tribes use brown twigs from the 'Toothbrush Tree' - Salvadora persica. The Swahili name is musuake and in Somali it is ade or adhei.

I took the liberty of having a twig analysed at Kew Gardens. It contains many substances, not least tri-methyl amine, high amounts of fluoride and silica, vitamin C, flavenoids and sterols. It is reported that it also has antibacterial properties, astringents and detergents. After several minutes of nibbling and chewing a twig, it frays into a fibrous mat not unlike a brush and leaves your teeth feeling really clean and smooth. I believe the company Sarakan Ltd in Beckenham put the powdered root in their products. There is no indication that it contains any toxic compounds but it may be worth checking.

I have also noticed a heavy dark brown stain on some patients' teeth but this is due to chewing the naturally available but mildly narcotic 'mirra' leaf which is horribly bitter. They therefore chew it with honey and sugar resulting in rampant decay - but that's another story.

R. O. Coleman, Cirencester DOI: 10.1038/sj.bdj.2011.529

\section{SHEATH COMPLIANCE}

Sir, further to the correspondence by R. Emanuel (Br Dent J 2011; 210: 344) concerning resheathing of needles, examination of the quoted EU directive states in Clause 6, Paragraph 1, 'Where the results of a risk assessment reveal a risk of injuries with a sharp..., only then is 'recapping' banned.

Risk assessment demonstrates when resheathing a dental local anaesthetic needle the operator's fingers are at least $3 \mathrm{~cm}$ away from the needle point; any healthcare professional who is unable to replace the sheath of such a needle without injuring his or herself is too clumsy to be allowed in a dental surgery.

To comply with HTM 01-05 the cleaning of instruments should be carried out in a room separate from the dental surgery. It is far more dangerous to handle and carry out transport of unsheathed 